\title{
METALLURGICAL AND CORROSION PROPERTY OF ADDITIVE MANUFACTURED TITANIUM ALLOY-Ti6AI4V
}

\author{
R. M. Mahamood1,2*, T. Marvins², K. 0. Abdulrahman, \\ Y. L. Shuaib-Babata², J. A. Adebisi², S. A. Akinlabi4, \\ S. Hassan ${ }^{4}$ E. T. Akinlabi ${ }^{1}$ \\ ${ }^{1}$ Department of Mechanical Engineering Science, University of Johannesburg, P O Box 524, Auckland park \\ 2006, South Africa \\ ${ }^{2}$ Department of Materials and Metallurgical Engineering, University of Ilorin, Nigeria \\ ${ }^{3}$ Department of Materials and Mechanical Engineering, University of Ilorin, Nigeria \\ ${ }^{4}$ Department of Mechanical Engineering, Butterworth Campus, Walter Sisulu University \\ * Corresponding author's e-mail address: mahamoodmr2009@gmail.com
}

\begin{abstract}
Additive manufacturing (AM) is an important manufacturing technology that has changed the way products are designed and manufactured. Laser Metal Deposition (LMD), an AM technology, has the capability of producing components using a 3Dimensional CAD model, through a layer by layer formation process just like any other AM technology. In this study, the influence of the scanning speed on the corrosion property of Titanium alloy-Ti6Al4V using LMD process was investigated. The scanning speed varied between $0.02 \mathrm{~m} / \mathrm{s}$ and $0.14 \mathrm{~m} / \mathrm{s}$ while other processing parameters were kept constant. The electrochemical corrosion test was conducted in sodium chloride $(\mathrm{NaCl})$ solution. The result revealed that the corrosion resistance property was found to increase with the scanning speed.
\end{abstract}

KEYWORDS: Additive Manufacturing, Corrosion, Laser Metal Deposition, Scanning speed, Titanium.

\section{INTRODUCTION}

Additive manufacturing (AM) is an advanced manufacturing process that has indeed revolutionize the manufacturing industries because of the flexibility that the process offers [1]. Laser Metal Deposition (LMD) is an Additive manufacturing technique that can produce components directly from three dimensional (3D) computer aided design (CAD) model of the part being made, through a layer by layer formation of materials [2], [3]. Apart from making a new product using LMD process, failed component can efficiently be repaired, and obsolete product can be remanufactured because of its ability to build a new product on an existing structure with good metallurgical bonding [4]. The ability of LMD to handle different materials simultaneously makes this $\mathrm{AM}$ process to be used in manufacturing product with composite and functionally grated materials [5]- [7]. Laser metal deposition process is highly sensitive to the processing parameters that govern the manufacturing process. These processing parameters include the laser power, scanning speed, powder flow rate and gas flow rate. These processing parameters have been demonstrated by researchers, to have great influence on the evolving properties of AM produced materials in general and laser metal deposited materials in particular [8]- [12]. Difficult to machine materials can easily be manufactured using LMD, no matter the complexity.

Titanium and its alloys are classified as difficult to machine materials due to the chemical behaviour of these materials [13]. Additive manufacturing technology is an excellent alternative manufacturing technology that can be used to process Titanium and its alloys [14]. Ti6Al4V is the most used titanium alloy and it is often referred to as the workhorse of the industry [15]. This is because of the exciting properties of Ti6A14V that includes: high strength to weight ratio, corrosion resistance and high biocompatibility [16]. These qualities have made Ti6Al4V a material of choice in industries such as the aerospace, automobile, chemical and biomedical industries [17], [18]. A few studies have appeared in the literature on the influence of the processing parameters on the properties of LMD processed Titanium and its alloys [19]-[22]. The properties that the processing parameters influence include, physical properties, hardness property, surface properties, and material deposition efficiencies [23]- [27]. The corrosion properties are also found to be influenced with the change in processing parameters [28], [29]. 
Some researchers studied the influence of heat treatment on corrosion behaviour of additively manufactured parts [30], [31]. The novelty of this current study is that the process parameters can be adjusted to improve the corrosion resistance of laser metal deposited part.

This present study investigates the influence of scanning speed on the corrosion behaviour of Ti6Al4V. The scanning speed was varied from 0.02 $\mathrm{m} / \mathrm{s}$ to $0.14 \mathrm{~m} / \mathrm{s}$ while all other processing parameters were kept at constant value throughout the experiments.

\section{EXPERIMENTAL PROCEDURE}

The Ti6Al4V substrate used in this study contains 6 $\mathrm{w} \%$ of aluminium, $4 \mathrm{w} \%$ of vanadium, supplied by VSMP-AVISMA corporation, a Russian based company. The Ti6Al4V powder used in this study is of particle size range between $120-320 \mu \mathrm{m}$ and it is spherically shaped atomized powder that was supplied by F.J Broadmann and Co Louisiana. The LMD process was achieved using the LMD experimental set-up consisting of a Kuka robot carrying a $3.0 \mathrm{KW}$ $\mathrm{Nd}$ :YAG laser attached to it end effector and with coaxial nozzles for powder delivery. This experimental set-up is available at the National Laser Centre (NLC) at the Council for Scientific and Industrial Research (CSIR) Pretoria, South Africa.

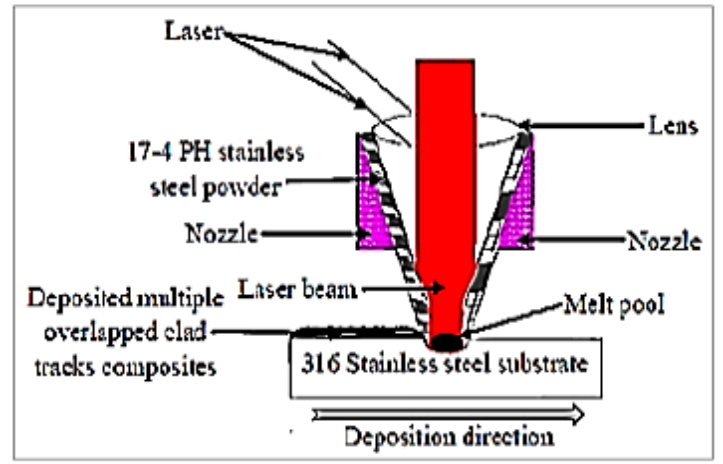

Fig. 1. Schematic diagram of LMD [32]

The laser spot size was maintained at a diameter of $2 \mathrm{~mm}$ and was focused at $195 \mathrm{~mm}$ above the substrate. A glove box filled with Argon gas was used to shield the deposited samples from reacting with oxygen in the atmosphere which can contaminate the results. The scanning speed was varied between 0.02 $-0.14 \mathrm{~m} / \mathrm{s}$. The laser power, the gas flow rate and the powder flow rate were kept constant at $3 \mathrm{~kW}, 41 / \mathrm{min}$ and $1.44 \mathrm{~g} / \mathrm{min}$, respectively. The LMD process was achieved by creating a melt pool on the surface of the substrate using the laser beam, then the powder was delivered through the coaxial powder nozzle onto the melt pool simultaneously and upon solidification a track of solidified melted powder was seen along the path of the laser. The schematic diagram of the LMD process is shown in figure 1 [32]. The experimental matrix used in this study is presented in table 1. After the deposition process, the samples for microstructural examination were cut across the deposition direction to reveal the cross section of the samples. The cut samples were mounted, ground and polished by the ASTM standard for metallurgical preparation of Titanium and its alloys [33].

Table 1. Process parameters

\begin{tabular}{|c|c|c|c|}
\hline $\begin{array}{c}\text { Laser } \\
\text { power } \\
{[\mathbf{k W}]}\end{array}$ & $\begin{array}{c}\text { Powder } \\
\text { flow rate } \\
\text { [g/min] }\end{array}$ & $\begin{array}{c}\text { Gas flow } \\
\text { rate } \\
{[\mathbf{l} / \mathbf{m i n}]}\end{array}$ & $\begin{array}{c}\text { Scanning } \\
\text { speed } \\
{[\mathbf{m} / \mathbf{s}]}\end{array}$ \\
\hline 3 & 1.44 & 4 & 0.02 \\
3 & 1.44 & 4 & 0.04 \\
3 & 1.44 & 4 & 0.06 \\
3 & 1.44 & 4 & 0.08 \\
3 & 1.44 & 4 & 0.10 \\
3 & 1.44 & 4 & 0.12 \\
3 & 1.44 & 4 & 0.14 \\
\hline
\end{tabular}

Electrochemical corrosion test was conducted on deposited samples which were cut into equal size coupons of area $0.35 \mathrm{~cm} \times 0.35 \mathrm{~cm}$. The coupons were immersed in corrosive media made of solution of $3.5 \mathrm{w} \% \mathrm{NaCl}$ dissolved in deionized water. The corrosion test set-up is shown in figure 2 . The test was conducted for 14 days to determine the corrosion rate of each of the samples. The polished samples were etched with Kroll's reagent consisting of $100 \mathrm{ml}$ of water and $3 \mathrm{ml}$ of hydrofluoric acid and $2 \mathrm{ml}$ of nitric acid. The Microstructure of samples were studied using optical microscope.

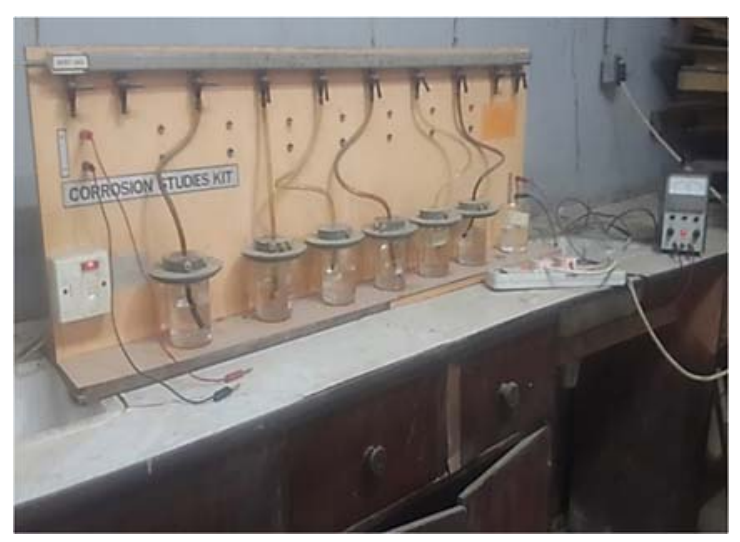

Fig. 2. Corrosion test experimental set-up

To predict the corrosion rate using Faraday's law, the following equations were used. The mass of metal lost to corrosion in grams is given in equation 1 as:

$$
m=I \cdot z \cdot t
$$

where I is the corrosion current $(\mu \mathrm{A})$; 
$\mathrm{t}$ - reaction time in second;

$\mathrm{z}$ - electrochemical equivalent $(\mathrm{g} / \mathrm{A} \cdot \mathrm{s})$.

$\mathrm{z}$ is given by the equation 2 :

$$
z=\frac{a}{n \cdot F}
$$

where a is the atomic weight of the corroding metal in grams;

$n$ - electron transfer in oxidation reaction in mole;

$F$ - Faraday's constant, $\mathrm{F}=96500 \mathrm{~A} \cdot \mathrm{s} / \mathrm{mole}$.

The Corrosion rate in mm per second $\left(C_{R}\right)$ is give in equation 3 as:

$$
\begin{gathered}
i_{\text {corr }}=\frac{I}{A} \\
C_{R}=\frac{m}{A \cdot T \cdot \rho}=\frac{i_{c o r r} \cdot z}{\rho}
\end{gathered}
$$

where $i_{\text {corr }}$ is the corrosion current density $\left(\mu \mathrm{A} / \mathrm{cm}^{2}\right)$;

$A$ - area exposed of metal to corrosion in $\mathrm{cm}^{2}$;

$\rho$ - density of metal $\left(\mathrm{g} / \mathrm{cm}^{3}\right)$.

The Corrosion rate per year (CR) based on the ASTM Standard G 102-89 [34] is given in equation 4 as:

$$
C R=\frac{K \cdot i_{\text {corr }} \cdot E W}{\rho}
$$

where $k$ is a constant $=3.2710^{-3} \mathrm{mmg} / \mu \mathrm{Acmyr}$

$E W$ - equivalent weight;

Density of $\mathrm{Ti} 6 \mathrm{Al} 14 \mathrm{~V}=4.43 \mathrm{~g} / \mathrm{cm}^{3}$ and $\mathrm{EW}$, equivalent weight of Ti6Al4V=11.90 [35].

\section{RESULTS AND DISCUSSION}

The microstructures of the samples were studied to gain insight into the influence of the scanning speed variation on the evolving microstructure that will in turn affect the properties of the deposited samples. Figure $3 \mathrm{a}$ and $\mathrm{b}$ shows the micrograph of the Ti6A14V powder and Ti6Al4V substrate.

The Ti6Al4V powder is spherically shaped gas atomised powder particle with few satellite particles connected to the larger particles. The shape of the powder is spherical due to the production process of the powder. The sphericity is important to maximize laser absorption. The Ti6Al4V substrate is characterize by the presence of alpha and beta phases which is an obvious characteristic of Ti6Al4V.

Figure $4 \mathrm{a}$ shows the micrograph of samples deposited at scanning speeds of $0.02 \mathrm{~m} / \mathrm{s}$ showing the columnar microstructure that is characteristic of laser metal deposition process. Similar microstructure is observed in all the samples which are characterized by columnar grains structures (Fig. 4a). The solidification process is directional because of the cold substrate that acted as heat sink during the deposition process. Globular grains are seen in the heat affected zone due to grain growth occurring at this area from the heat gained from the melt pool. The globular gains are where the columnar grains grew on epitaxially. As the scanning speed was increasing, the population of the columnar grains increase because of rapid cooling due to smaller melt pool size which is consistent with was obtained in the previous study [23].

The higher magnification of samples deposited at scanning speeds of $0.04 \mathrm{~m} / \mathrm{s}$ and $0.12 \mathrm{~m} / \mathrm{s}$ are shown in figure $4 \mathrm{~b}$ and $4 \mathrm{c}$ respectively. The microstructure of the deposited sample at lower scanning speed is characterized by basket woven microstructure due to the lower solidification rate at low scanning speed (Fig. 4b). The melt pool produced at low scanning speed is large because of larger laser material-interaction time that causes slower cooling rate. At high scanning speed, the cooling rate is much more rapid, and the evolving microstructure is martensitic structure (Fig. 4c).

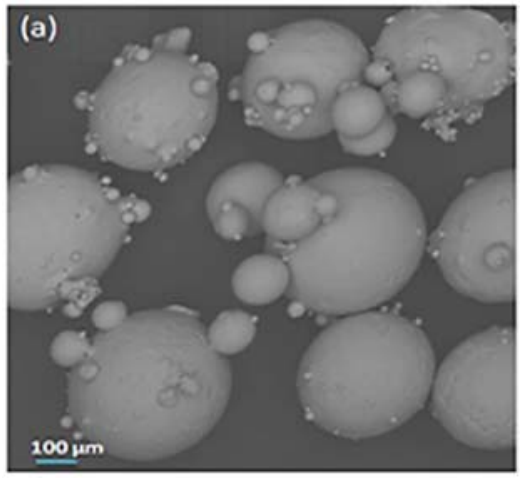

a)

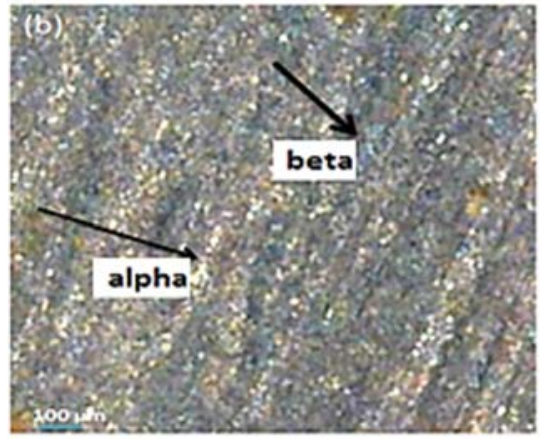

b)

Fig. 3. a) Micrograph of Ti6Al4V powder. b) Optical micrograph of substrate

The results of the electrochemical corrosion test carried out on the deposited samples in corrosive media of $\mathrm{NaCl}$ are presented in Table 4 . The results were obtained by using the average corrosion current that were read during the corrosion test and applying 
the equation (3) to obtain the corrosion current density. This is subsequently used in equations (4) and (5) to obtain the corrosion rate.
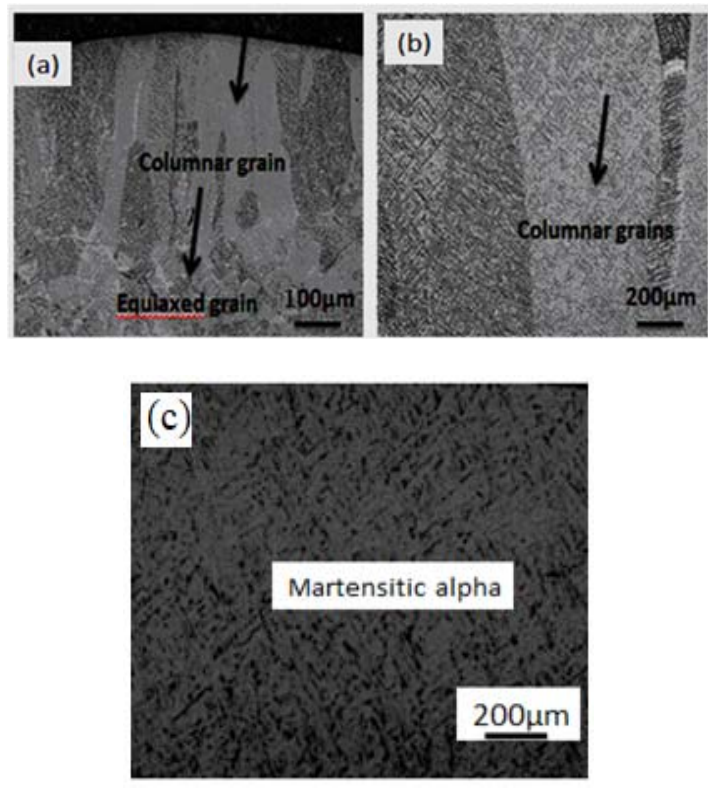

Fig. 4. Optical micrograph of sample produced at (a) scanning speed of $0.02 \mathrm{~m} / \mathrm{s}$ (b) scanning speed of 0.04 $\mathrm{m} / \mathrm{s}$ (c) scanning speed of $0.12 \mathrm{~m} / \mathrm{s}$

Table 4. Electrochemical corrosion test results

\begin{tabular}{|c|c|c|}
\hline $\begin{array}{c}\text { Scanning } \\
\text { speed }(\mathbf{m} / \mathbf{s})\end{array}$ & $\begin{array}{c}\text { Corrosion } \\
\text { current density } \\
\mathbf{i}_{\text {corr }\left[\boldsymbol{\mu A} / \mathbf{c m}^{2}\right]}\end{array}$ & $\begin{array}{c}\text { Corrosion rate } \\
{[\mathbf{m m} / \mathbf{y r}]}\end{array}$ \\
\hline 0.02 & 16.3265 & 0.14341153 \\
0.04 & 13.0612 & 0.11472923 \\
0.06 & 12.2449 & 0.10755887 \\
0.08 & 12.2449 & 0.10755887 \\
0.10 & 10.6122 & 0.09321728 \\
0.12 & 9.7959 & 0.08604692 \\
0.14 & 8.9796 & 0.07887656 \\
\hline
\end{tabular}

The graph of corrosion current density against the scanning speed is shown in figure 5 . The bar chart of corrosion rate per year $(\mathrm{mm} / \mathrm{yr})$ is presented in figure 6 . The corrosion current density is found to decrease as the scanning speed was increased. The corrosion rate per year is also seen to de decreasing as the scanning speed was increased. The highest corrosion rate observed at the lowest scanning speed is 0.1434 $\mathrm{mm} / \mathrm{yr}$ is far less than the corrosion rate of the substrate which is $0.3911 \mathrm{~mm} / \mathrm{yr}$. This could be as a result of the rapid solidification that characterizes the LMD process which often results in improved properties of the deposited materials [23].

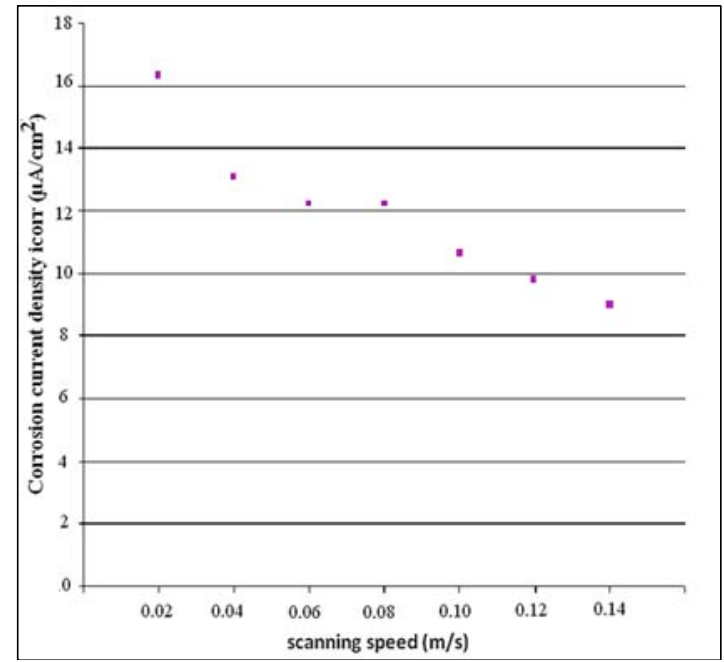

Fig. 5. Graph of corrosion current density against the scanning speed

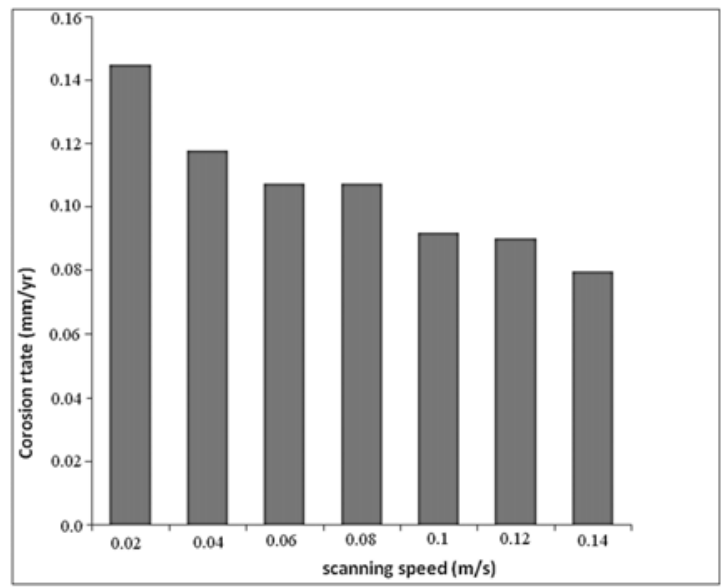

Fig. 6. Bar chart of corrosion rate per year against scanning speed

At low scanning speed, the laser reacts with the deposited powder at a much longer time that enables proper melting of the powder and also results in larger melt pool that stays longer on the substrate before finally solidifies. This will result in the development of microstructure that include Widsmanstateen (bascketwoven) as seen in Figure $4 \mathrm{~b}$, that is softer in nature. This could be the reason for the high corrosion rate that was observed at the lower scanning speed as compared to at higher scanning speed.

At higher scanning speeds, the interaction between the laser beam and the deposited powder is shorter and hence, the melt pool that was created is smaller which solidifies much more rapidly and developed martensitic microstructure (Fig. 4c) which is much harder and hence producing lower corrosion rate. These observations are consistent with the results observed from studies in the literature [23]. 


\section{CONCLUSIONS}

This paper investigated the effect of scanning speed on the corrosion behaviour of laser metal deposited Ti6Al4V. The scanning speed was varied between 0.02 and $0.14 \mathrm{~m} / . \mathrm{s}$ while all the remaining process parameters were kept constant throughout the experiments. This study revealed that as the scanning speed was increased, the corrosion rate per year was found to be decreasing. Also, the highest corrosion rate of $0.1434 \mathrm{~mm} / \mathrm{yr}$ observed at a scanning speed of $0.02 \mathrm{~m} / \mathrm{s}$ is lower than the corrosion rate of that of the substrate which is $0.3911 \mathrm{~mm} / \mathrm{yr}$. The optimum scanning speed in this study can be concluded to be the speed that produced the lowest corrosion rate of $0.0789 \mathrm{~mm} / \mathrm{yr}$ which is obtained at the highest scanning speed of $0.14 \mathrm{~m} / \mathrm{s}$ based on the set of processing parameters that were considered in this study.

\section{ACKNOWLEDGEMENTS}

The authors acknowledged the support of National Laser Centre, Centre for Scientific and Industrial Research (CSIR), Pretoria, South Africa for the laser equipment used in this project.

\section{REFERENCES}

[1] Craveiro F., Duarte J.P., Bartolo H., Bartolo P.J., Additive manufacturing as an enabling technology for digital construction: A perspective on Construction 4.0, Automation in Construction, vol. 103, 2019, pp. 251-267.

[2] Mahamood R. M., Laser metal deposition process of metals, alloys, and composite materials, Springer Cham, Switzerland, 2018.

[3] Scott J., Gupta N., Wember C., Newsom S., Wohlers T., Caffrey T. Additive manufacturing: status and opportunities, Science and Technology Policy Institute, 2012. Available from: https://www.ida.org/stpi/occasionalpapers/papers/AM3D_33012_Fi nal.pdf (Accessed on 11 July 2019).

[4] Mahamood R. M., Akinlabi E. T., Owolabi M. G., Laser Metal Deposition Process for Product Remanufacturing. In: Gupta K. (eds) Advanced Manufacturing Technologies. Materials Forming, Machining and Tribology. Springer, Cham 2017, pp. 267-291.

[5] Nam S., Cho H., Kim, C., Kim, Kim Y. M., Effect of process parameters on deposition properties of functionally graded STS 316/Fe manufactured by laser direct metal deposition, Metals, vol. 8(8), 2018, pp. 607-622.

[6] Liu W., Dupout J., Fabrication of Functional Graded TiC Carbide in Laser Engineered Net Shaping, Scripta Matr, 9(48), 2003, pp. 1337.

[7] Adeyemi A. A, Akinlabi E. T., Mahamood R. M., Microstructural evolution of laser metal deposited 17-4 PH SStungsten composite with varying volume percent tungsten. Annals of "Dunarea de Jos" University of Galati, Fascicle XII, Welding Equipment and Technology, vol. 29, 2018, pp. 41-46.

[8] Masaylo D., Igoshin S., Popovich A., Popovich V., Effect of process parameters on defects in large scale components manufactured by direct laser deposition, Materials Today: Proceedings, 2020.

[9] Carrullo J. C. Z., Falcón J. C. P., Borrás V. A., Influence of process parameters and initial microstructure on the oxidation resistance of Ti48Al2Cr $2 \mathrm{Nb}$ coating obtained by laser metal deposition, Surface and Coatings Technology, vol. 358, 2019, pp. 114-124.
[10] Silze F., Schnick M., Sizova I., Bambach M., Laser Metal Deposition of Ti-6Al-4V with a Direct Diode Laser Set-up and Coaxial Material Feed, Procedia Manufacturing, vol. 47, 2020, pp. 1154-1158.

[11] Mahamood R. M., Akinlabi E. T., Scanning speed and powder flow rate influence on the properties of laser metal deposition of titanium alloy, The International Journal of Advanced Manufacturing Technology, vol. 91 (5-8) 2017.

[12] Rosenthal Y., Apelstein Y., Rosenthal L., Ashkenazi D., Stern A., On Laser Powder-Bed Fusion of Additively Manufactured AlSi10Mg alloy: tensile properties and structure characterization, Annals of "Dunarea de Jos" University of Galati, Fascicle XII, Welding Equipment and Technology, vol. 30, 2019 , pp. 5-11.

[13] Machado A. R., Wallbank J., Machining of Titanium and its Alloys: A Review, Proceedings of the Institution of Mechanical Engineers Part B: Management and Engineering Manufacture, vol. 204(11), 2005, pp. 53-60.

[14] Donachi M. J., Titanium-A technical guide, 2nd ed. ASM International. 2000.

[15] Ramesh S., Karunamoorthy L., Palanikumar K., Surface Roughness Analysis in Machining of Titanium Alloy. Materials and Manufacturing Processes, vol. 23(2), 2008, pp. 174-181.

[16] Cui X. H., Mao Y. S., Wei M. X., Wang S. Q., Wear Characteristics of Ti-6Al-4V Alloy at $20-400^{\circ} \mathrm{C}$, Tribology Transactions, 55(2), 2012, pp. 185-190.

[17] Lütjering G., Williams J. C., Titanium, Springer, Berlin, Germany, 2003.

[18] Nalla R. K., Boyce B. L., Campbell J. P., Peters J. O., Ritchi R. O., Influence of microstructure on high-cycle fatigue of Ti-6al-4v: bimodal vs. lamellar structures, Metallurgical And Materials Transactions A, vol. 33a, 2002, pp. 899-918.

[19] Mahamood R. M., Akinlabi E. T., Effect of Processing Parameters on Wear Resistance Property of Laser Material Deposited Titanium -Alloy Composite, Journal of Optoelectronics and Advanced Materials, vol. 17 (9-10), 2015, pp. 1348-136.

[20] Pityana S., Mahamood R. M., Akinlabi E. T., Shukla M., Gas flow rate and powder flow rate effect on properties of laser metal deposited Ti6Al4 V, IMECS 2013

[21] Azarniya A., Colera X. G., Mirzaali M. J., Sovizi S. Bartolomeu F., Weglowski M., Wits W. W., Yap C. Y., Ahn J., Miranda G., Silva F. S., Hosseini H. R. M., Ramakrishna S., Zadpoor A. A., Additive manufacturing of $\mathrm{Ti}-6 \mathrm{Al}-4 \mathrm{~V}$ parts through laser metal deposition (LMD): Process, microstructure, and mechanical properties, Journal of Alloys and Compounds, vol. 804, 2019, pp. 163-191.

[22] Wołosz P., Baran A., Polański M., The influence of laser engineered net shaping (LENS ${ }^{\mathrm{TM})}$ technological parameters on the laser deposition efficiency and properties of H13 (AISI) steel, Journal of Alloys and Compounds, vol. 823, 2020.

[23] Mahamood R. M., Akinlabi E. T., Scanning speed influence on the microstructure and micro hardness properties of titanium alloy produced by laser metal deposition process, Materials today: Proceedings, vol. 4 (4), 2017, pp. 5206-5214.

[24] Li W., Zhang J., Zhang X., Liou F., Effect of optimizing particle size on directed energy deposition of Functionally Graded Material with blown Pre-Mixed Multi-Powder, Manufacturing Letters, vol. 13, 2017, pp. 39-43.

[25] Silze F., Schnick M., Sizova I., Bambach M., Laser Metal Deposition of Ti-6Al-4V with a Direct Diode Laser Set-up and Coaxial Material Feed, Procedia Manufacturing, vol. 47, 2020 , Pages 1154-1158.

[26] Sreeramagiri P., Bhagavatam A, Alrehaili H., Dinda G., Direct laser metal deposition of René 108 single crystal superalloy, Journal of Alloys and Compounds, vol. 838, 2020, ISSN 09258388, https://doi.org/10.1016/j.jallcom.2020.155634.

[27] Froend M., Riekehr S., Kashaev S., Klusemann B., Enz J., Process development for wire-based laser metal deposition of 5087 aluminium alloy by using fibre laser, Journal of Manufacturing Processes, vol. 34, Part A, 2018, pp. 721-732.

[28] Sun S. D., Fabijanic D., Annasamy M., Gallo S. C., Fordyce I., Paradowska A., Leary M., Easton M., Brandt M., Microstructure, abrasive wear and corrosion characterisation of laser metal deposited $\mathrm{Fe}-30 \mathrm{Cr}-6 \mathrm{Mo}-10 \mathrm{Ni}-2.2 \mathrm{C}$ alloy, Wear, 2019, pp. 438-439. 
[29] Wen J-H., Zhang L-J., Ning J., Xue F., Lei, Wei X-W., Zhang J-X., Na S-J., Laser additively manufactured intensive dual-phase steels and their microstructures, properties and corrosion resistance, Materials \& Design, vol. 192. 2020, https://doi.org/10.1016/j.matdes.2020.108710.

[30] Chandramohan, P., Bhero, S., Obadele, B.A., Olubambi P.A.,. Laser additive manufactured Ti-6AI-4V alloy: tribology and corrosion studies. International Journal of Advanced Manufacturing Technology, vol. 92, 2017, pp.3051-3061.

[31] Yang J., Yang H., Yu H., Wang Z., Zeng X., Corrosion Behavior of Additive Manufactured Ti-6Al-4V Alloy in $\mathrm{NaCl}$ Solution, Metallurgical and Materials Transactions A, vol. 48 (7), 2017, pp. 3583-3593.
[32] Adeyemi A. A., Akinlabi E. T., Mahamood R. M., Influence of Laser power on Microhardness and Wear Resistance Properties of Laser Metal Deposited 17-4 PH Stainless Steel, Annals of "Dunarea de Jos" University of Galati, Fascicle XII, Welding Equipment and Technology, vol. 29, 2018, pp. 57-63

[33] ASTM E2-11. standard for preparation of metallorgaphic specimen. ASTM internatinal, 2011, www.astm.org.

[34] ASTM Standard G 102-89, Standard Practice for Calculation of Corrosion Rates and Related Information from Electrochemical Measurements 2014

[35] Burnat1 B., Walkowiak-Przybyło M., Blaszczyk T., Klimek L., Corrosion behaviour of polished and sandblasted titanium alloys in PBS solution, Acta of Bioengineering and Biomechanics, Vol. 15, No. 1, 2013, pp. 87-95. 